\title{
Diaphragm electrical activity monitoring as a breakpoint in the management of a tetraplegic child
}

\author{
Guillaume Mortamet ${ }^{*}$ D, François Proulx, Benjamin Crulli, Nadia Savy, Philippe Jouvet and Guillaume Emeriaud
}

Keywords: Mechanical ventilation, Electrical activity of the diaphragm, Diaphragm function, Pediatric intensive care unit, Pediatrics

Over the last decade, new technology has been developed to continuously record the electrical activity of the diaphragm (EAdi) at the bedside [1]. EAdi monitoring has been shown to be useful in assessing the patient's ventilatory drive, in adjusting ventilatory support, and in detecting patient-ventilator asynchrony [2-4]. In the present case, we highlight how monitoring EAdi could be a sensitive diagnostic tool to detect spontaneous respiratory cycles in a mechanically ventilated child with tetraplegia.

An 8-year-old girl was admitted to our pediatric intensive care unit (PICU) for a rapidly progressive right hemiparesis. The CT scan revealed a large C3-C4 medullary arteriovenous malformation predominantly. An urgent embolization was attempted, but severe edema and hemorrhagic transformation of venous thrombosis developed, leading to tetraplegia with dysautonomia. She underwent tracheostomy on day 12 due to the absence of spontaneous breathing. Three months later, an MRI scan showed extensive cervical cord fibrosis and atrophy at C2-C3-C4 levels (Fig. 1). On day 90, a phrenic nerve stimulation test was conducted to assess the potential for diaphragmatic pacing. No esophageal pressure deflection was induced by the stimulation. However, after a few respiratory pauses applied for the stimulation, we noted some spontaneous cycles on the EAdi recordings (about $5 \mu \mathrm{V}$ ) associated with esophageal pressure deflections $\left(5-10 \mathrm{cmH}_{2} \mathrm{O}\right)$. Continuous monitoring of EAdi was performed while decreasing the level of ventilator support, thereby confirming an intermittent and small respiratory drive (Fig. 2). Weaning using NAVA was started in order to favor the patient's own respiratory drive, which gradually increased over time (Fig. 2). She was progressively and successfully weaned from the ventilator during daytime on day 162 and the patient was discharged home on day 374 .

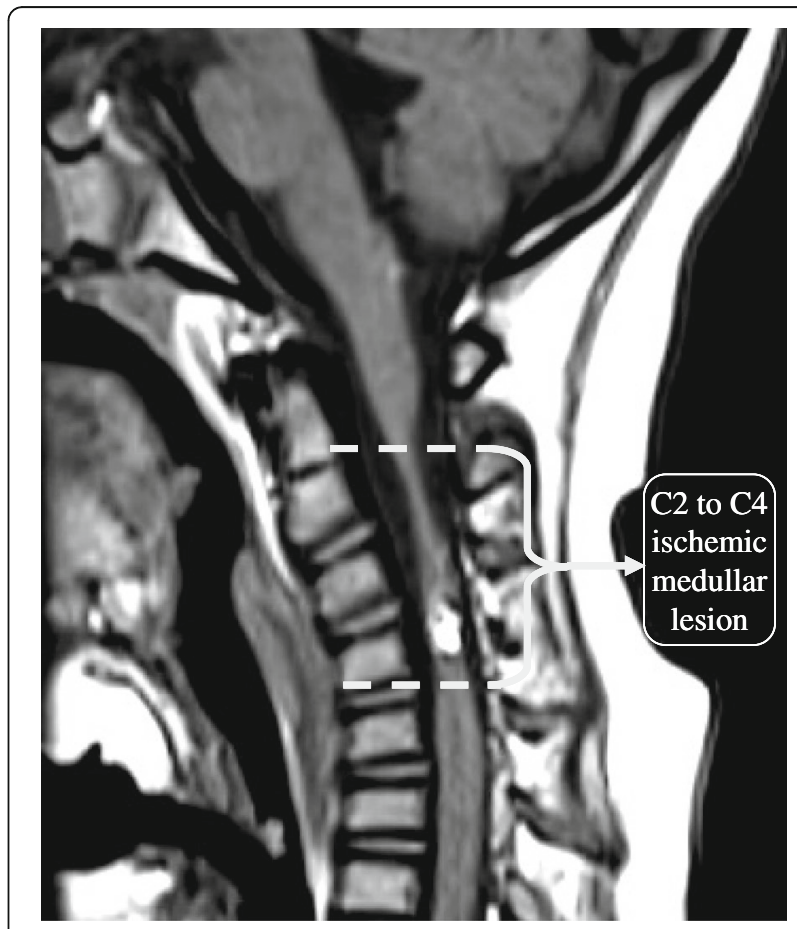

Fig. 1 Brain MRI image (T2-weighted) performed on day 90 showing extensive cervical cord fibrosis and atrophy, which was more severe at C2-C3-c4 levels

* Correspondence: mortam@hotmail.fr

Paediatric Intensive Care Unit, CHU Sainte-Justine, 3175 Côte

Sainte-Catherine, Montreal, QC H3T 1C5, Canada 


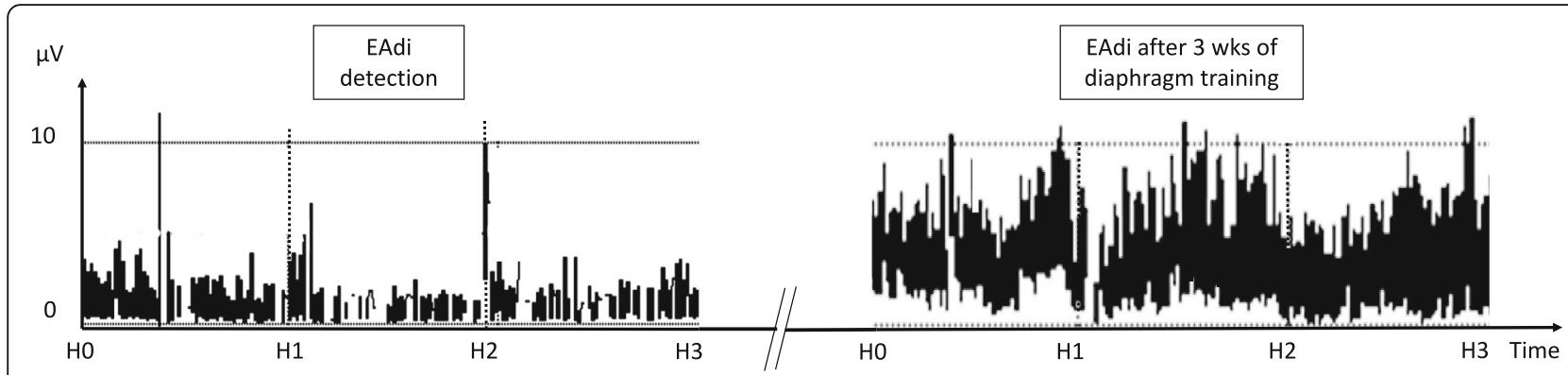

Fig. 2 Evolution of diaphragm electrical activity (EAdi) over 3-hour recordings ( $\mathrm{HO}$ to $\mathrm{H} 3$ ) at the time of diagnosis of the present ventilatory drive (left panel), showing intermittent EAdi at low levels, to 3 weeks (wks) later (right panel), after weaning in NAVA, showing sustained and higher levels of EAdi

Although it was not observed clinically, residual respiratory activity was evidenced by the EAdi monitoring. We hypothesize that complete ventilatory support during the first 3 months may have induced some diaphragmatic dysfunction [5], making it difficult to detect a respiratory drive. While we were initially considering the implantation of a diaphragmatic pacing device, we instead opted for a ventilation weaning challenge using NAVA, which allowed a gradual decrease in the level of support while preserving spontaneous breathing and diaphragm training.

This case illustrates that clinical assessment could lack sensitivity in detecting spontaneous breathing in patients with low respiratory drive. EAdi monitoring may be considered to precisely assess the presence of spontaneous breathing in complex patients, especially before making important management decisions.

\section{Abbreviations}

$\mathrm{CT}$ : Computerized tomography; EAdi: Electrical activity of the diaphragm; MRI: Magnetic resonance imaging; NAVA: Neurally adjusted ventilatory assist; PICU: Pediatric intensive care unit

\section{Acknowledgements}

The authors acknowledge the patient and her family, who gave their consent for this case report.

\section{Funding}

None.

Availability of data and materials

Not applicable.

\section{Authors' contributions}

$B C, F P, P J$, and GE were involved in patient care. GM, FP, NS, and BC carried out the chart review and data collection. GE obtained and analyzed the data on EAdi, and led the case report review and submission. GM wrote the manuscript, which was reviewed, edited, and approved by all authors. As the corresponding author, GM has full access to all the data in the study and has final responsibility for the decision to submit for publication.

\section{Competing interests}

PJ is supported by a scholarship award of the Fonds de Recherche du Québec-Santé, Ministry of Health and Sainte-Justine Hospital; was a consultant for Sage Therapeutic Inc;; and was invited to a congress by Medunik Inc and Covidien. GE's research program is supported by a scholarship award by the Fonds de Recherche du Québec-Santé; and
GE is currently leading a feasibility study in neonatal ventilation which is financially supported by Maquet Critical Care. The remaining authors declare that they have no competing interests.

\section{Consent for publication}

Written informed consent was obtained from the patient and her family for publication of their individual details and accompanying images in this manuscript. The consent form is held by the authors and is available for review by the Editor-in-Chief.

Ethics approval and consent to participate Not applicable.

\section{Publisher's Note}

Springer Nature remains neutral with regard to jurisdictional claims in published maps and institutional affiliations.

Published online: 26 May 2017

\section{References}

1. Beck J, Gottfried SB, Navalesi P, Skrobik Y, Comtois N, Rossini M, Sinderby C. Electrical activity of the diaphragm during pressure support ventilation in acute respiratory failure. Am J Respir Crit Care Med. 2001;164:419-24.

2. Bellani G, Mauri T, Coppadoro A, Grasselli G, Patroniti N, Spadaro S, Sala V, Foti $G$, Pesenti A. Estimation of patient's inspiratory effort from the electrical activity of the diaphragm. Crit Care Med. 2013;41:1483-91.

3. Ducharme-Crevier L, Du Pont-Thibodeau G, Emeriaud G. Interest of monitoring diaphragmatic electrical activity in the pediatric intensive care unit. Crit Care Res Pract. 2013;2013:384210.

4. Colombo D, Cammarota G, Bergamaschi V, De Lucia M, Corte FD, Navalesi P. Physiologic response to varying levels of pressure support and neurally adjusted ventilatory assist in patients with acute respiratory failure. Intensive Care Med. 2008;34:2010-8.

5. Jaber $S$, Petrof $B J$, Jung $B$, Chanques $G$, Berthet JP, Rabuel $C$, Bouyabrine $H$, Courouble $P$, Koechlin-Ramonatxo C, Sebbane M, Similowski T, Scheuermann V, Mebazaa A, Capdevila X, Mornet D, Mercier J, Lacampagne A, Philips A, Matecki S. Rapidly progressive diaphragmatic weakness and injury during mechanical ventilation in humans. Am J Respir Crit Care Med. 2011;183:364-71. 